\title{
Educação Ambiental: referências teóricas no ensino superior
}

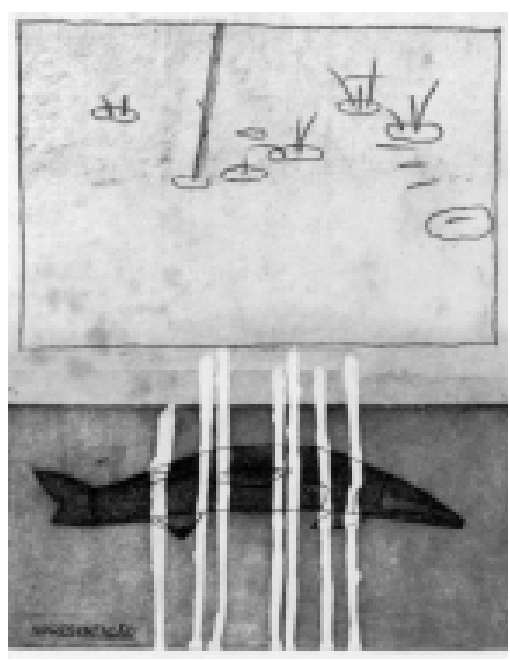

\author{
Marília Freitas de Campos Tozzoni-Reis ${ }^{1}$
}

TOZZONI-REIS, M. F. C. Environmental education: theoretical references in higher education, Interface Comunic, Saúde, Educ, v.5, n.9, p.33-50, 2001.

This article discusses the theoretical assumptions present in the training of environmental educators in undergraduate courses. These assumptions define a theoretical picture when they are analyzed through the methodological reference of historical-dialectic materialism. This theoretical picture can be organized into natural, rational and historical concepts of the man-nature relation and of education, and analysis suggests methodological principles of curricular organization for these courses.

KEY-WORDS: Education; environmental educators; nature; theoretical models.

Este artigo trata dos pressupostos teóricos presentes na formação dos educadores ambientais nos cursos de graduação. Esses pressupostos definem um quadro teórico analisado a partir do referencial metodológico do materialismo histórico-dialético. Esse quadro teórico pode ser organizado em concepções naturais, racionais $e$ históricas da relação homem-natureza e da educação e suas análises sugerem princípios metodológicos de organização curricular nesses cursos.

PALAVRAS-CHAVE: Educação; educação ambiental; natureza; modelos teóricos.

\footnotetext{
${ }^{1}$ Professora do Departamento de Educação, Instituto de Biociências, Universidade Estadual Paulista, Unesp/Botucatu, SP. <btmarili@terra.com.br>
} 


\section{Introdução}

As discussões sobre a Educação Ambiental no mundo contemporâneo estão relacionadas àquelas mais gerais sobre as questões ambientais que têm feito parte das preocupações dos mais variados setores da sociedade. Desde a Revolução Industrial, a atividade interventora e transformadora do homem em sua relação com a natureza vem se tornando cada vez mais predatória. A vida humana e a de outras espécies encontram-se concretamente ameaçadas. Essa profunda crise, a maior crise da história humana pela abrangência planetária, tem conseqüências para a área da Educação. Podemos dizer que as preocupações com a relação educação/ambiente não são novas e já estavam presentes de alguma forma, por exemplo, em Comenius, Rousseau, Pestallozi, Froebel e Freinet.

Se a problemática ambiental e a Educação Ambiental tornaram-se temas importantes nas discussões da relação dos homens com o ambiente na atualidade, nos cursos de graduação esses temas têm ocupado cada vez mais espaço. Estamos formando nesses cursos, mesmo que de forma assistemática, profissionais que atuarão direta ou indiretamente como educadores ambientais. Qual o campo teórico que fundamenta essa formação?

Este artigo apresenta as principais análises empreendidas pela pesquisa da tese de doutorado defendida na Faculdade de Educação da UNICAMP (Campos, 2000), que teve como objetivo compreender as formulações teóricas que fundamentam as práticas de formação dos educadores ambientais nos cursos de graduação de Instituições de Ensino Superior. Aquele estudo definiu, para investigação, as representações dos professores dos cursos de Biologia, Química e Geografia das universidades públicas do Estado de São Paulo acerca da Educação Ambiental. Essas representações foram analisadas a partir das entrevistas realizadas com os professores que desenvolvem as atividades de formação de educadores ambientais nesses cursos.

As reflexões empreendidas acerca dos resultados das investigações, permitiram formular a tese de que a formação dos educadores ambientais nos cursos de graduação das universidades é fundamentada por diferentes formulações teóricas, que podem indicar tentativas de superação dos paradigmas tradicionais de interpretação da realidade.

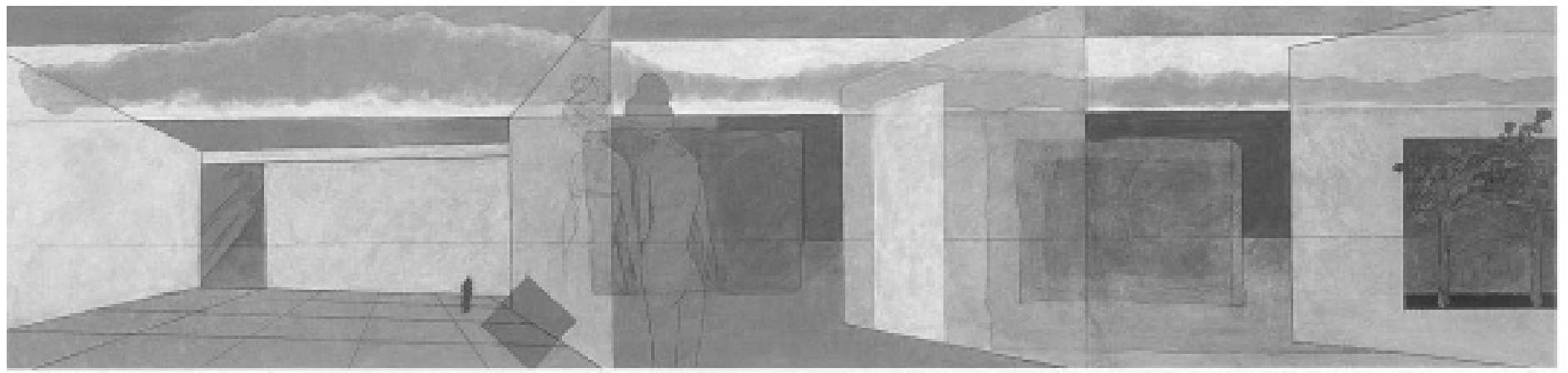




\section{O problema da metodologia na pesquisa}

Compreendo como metodologia na pesquisa o caminho para a construção do conhecimento, relacionado tanto às referências teóricas quanto às técnicas e instrumentos de investigação. Para analisar as formulações teóricas acerca da Educação Ambiental, tomei o materialismo históricodialético como referencial metodológico.

No que diz respeito ao campo teórico da questão ambiental, muitas alternativas têm sido discutidas. As tendências presentes nessas discussões referem-se, em síntese, à totalidade, à complexidade e à história. A idéia é de superação da fragmentação presente na prática histórica de construção do conhecimento; assim, o holismo (Capra, 1993; Prigogine E Stengers, 1997) e a teoria da complexidade (Morin \& Marques, s.d.) têm ocupado a cena com destaque.

No entanto, foi na dialética de Marx, construção lógica do método materialista histórico, que busquei apoio teórico-metodológico (instrumento lógico) de interpretação da realidade ambiental e educacional. Se a lógica formal, porque é dual separando sujeito-objeto, foi se mostrando insuficiente para a tarefa de analisar a Educação e a Educação Ambiental, pareceu-me possível buscar no método materialista histórico-dialético esse caminho.

Na busca de um caminho epistemológico para fundamentar a interpretação da realidade histórica e social, Marx \& Engels (1979) propuseram superar (no sentido de incorporar e ir além) - e colocar de cabeça para baixo - as formulações de Hegel sobre a dialética, conferindolhe um caráter materialista e histórico. Para o pensamento marxista, importa descobrir as leis dos fenômenos de cuja investigação se ocupa, importa captar detalhadamente as articulações dos problemas de estudo, analisar as evoluções, rastrear as conexões entre os fenômenos que os envolvem. A separação sujeito-objeto promovida pela lógica formal não satisfazia a esses pensadores que, na busca da superação desta separação, partiram de observações acerca do movimento e da contraditoriedade do mundo, dos homens e de suas relações (Pires, 1997).

A lógica formal não consegue explicar as contradições e amarra o pensamento, impedindo-lhe o movimento necessário para a compreensão das coisas. Se o mundo é dialético (movimenta-se e é contraditório) é preciso um método, uma teoria de interpretação, que consiga servir de instrumento para sua compreensão, e este instrumento lógico pode ser o método dialético tal como pensou Marx.

Nesse caminho lógico, movimentar o pensamento significa refletir sobre a realidade partindo do empírico (a realidade dada, o real aparente, o objeto assim como se apresenta à primeira vista) e pelas abstrações (elaborações do pensamento, reflexões, teoria) chegar ao concreto (compreensão mais elaborada do que há de essencial no objeto, concreto pensado). Assim, a diferença entre o empírico (real aparente) e o concreto (real pensado) são as abstrações (reflexões) do pensamento que tornam mais completa a realidade observada (Saviani, 1991).

As contribuições desse método de interpretação são os caminhos 
metodológicos por ele oferecidos. Em seus estudos sobre metodologia da investigação, Marx (1983) descobre a necessidade de definição de uma categoria inicial de análise, tão simples que possa ser tomada imediatamente pelo pesquisador como ponto de partida, como fundamental e, ao mesmo tempo, tão complexa que possa oferecer as maiores possibilidades de reflexão e análise, para que, de real aparente seja apropriada como real concreta. A essa categoria, Marx chamou de categoria simples, síntese de múltiplas determinações. Para Marx, nas análises econômicas de O Capital, a categoria simples (empírica) é a mercadoria, da qual foi possível, a partir de abstrações, compreender a economia capitalista.

Para a investigação e interpretação de uma dada realidade, o método materialista histórico-dialético oferece esse primeiro caminho: a definição de categoria simples, síntese de múltiplas determinações. Nesse sentido, foi preciso definir esta categoria para o estudo da Educação Ambiental. Na definição do ponto de partida para as análises pretendidas, algumas leituras trouxeram as primeiras pistas. Num primeiro momento, as idéias sobre conscientização, participação, reflexão, conhecimento da realidade ambiental, identificação da dimensão sócio-política da temática ambiental etc., foram se apresentando como importantes para as análises sobre a formação dos educadores ambientais nas universidades. Os princípios metodológicos de caráter pedagógico como interdisciplinaridade, socialização do conhecimento, formação reflexiva etc., também fizeram parte dessa busca de categorias de análise.

Foi preciso, então, clarear o conceito de categoria simples, síntese de múltiplas determinações. A comparação feita por Marx (1968) entre a categoria de análise econômica mais usada pelos economistas, a população, $e$ sua categoria simples, a mercadoria, foram esclarecedoras. Essas aproximações que vinha tentando, embora apresentassem categorias importantes para análise, pareciam-me amplas demais para se tornarem categorias simples, sínteses da Educação Ambiental, porque cada uma delas apresentava-se muito complexa, levando a um conjunto de determinações diferentes e divergentes.

A Educação Ambiental exige duas dimensões para análise: a dimensão epistemológica e a dimensão pedagógica. Isso porque exige reflexões acerca da problemática ambiental e da Educação.

No entanto, foi pela aproximação a essas categorias, pensando sobre elas, tentando mergulhar em suas determinações, que pude encontrar, de forma ainda bastante provisória, uma pista fundamental para pensar as questões ambientais mais gerais e a Educação Ambiental em particular, especialmente pelo seu caráter essencialmente histórico: a problemática da intervenção humana no ambiente (Marx, 1993). Este ponto pareceu-me central para pensar as categorias de análise da educação ambiental em suas duas dimensões, pois a intervenção humana no ambiente parece sintetizar elementos para a compreensão da problemática ambiental, mas também sintetiza, por seu caráter intencional, a problemática educacional.

Assim, a intervenção humana no ambiente apresentou a relação homem-natureza como possibilidade de problematização da Educação Ambiental, isto é, apresentou-a como categoria simples, e porque 
fundamental, síntese de múltiplas determinações a serem desvendadas durante minhas reflexões. No entanto, se essa categoria parecia indicar caminhos para pensar a Educação Ambiental principalmente em sua dimensão epistemológica, era preciso buscar uma categoria mais própria para pensá-la em sua dimensão pedagógica. Voltando à intervenção humana no ambiente, na relação homem-natureza, qual seria a categoria que permitiria compreender, nessa linha, a dimensão pedagógica da Educação Ambiental nas representações dos professores? A representação da educação mostrou-se própria para sintetizar os elementos necessários para compreender a intencionalidade da intervenção humana no ambiente, síntese das formulações teóricas dos professores sobre Educação Ambiental em sua dimensão pedagógica. Assim, as entrevistas e a análise dos dados centraram-se nessas duas categorias - relação homem-natureza e educação -, ainda que algumas outras tenham auxiliado nas interpretações.

\section{Natureza, razão e história: tendências reveladas}

As análises dos resultados coletados nas entrevistas demonstraram concepções que revelam, tendencialmente, um quadro teórico de representações cujo núcleo pode ser organizado em tendência natural, tendência racional e tendência histórica, determinadas segundo as trajetórias acadêmico-profissionais dos professores entrevistados.

As formulações que se identificam como tendência natural representam a relação homem-natureza pela idéia de que a posição do homem no ambiente é definida pela própria natureza e de que a educação, em particular a ambiental, tem como função reintegrar o homem à natureza $e$, por conseqüência, adaptálo à sociedade. Uma das concepções desta relação, presente principalmente entre os professores dos cursos de Biologia, resulta de uma compreensão que naturaliza as relações dos indivíduos com o ambiente em que vivem, sendo a relação homem-natureza definida pela própria natureza. Desta forma, a crise ambiental surge como uma disfunção circunstancial, $e$ a idéia de que a humanidade encerrou as possibilidades históricas e sociais, intencionais - teórica e politicamente - de convivência humana e ambiental são seus mais expressivos conteúdos. A natureza natural, nesta concepção, ocupa a centralidade da vida social. As impossibilidades filosófico-políticas dessa concepção orgânica da relação

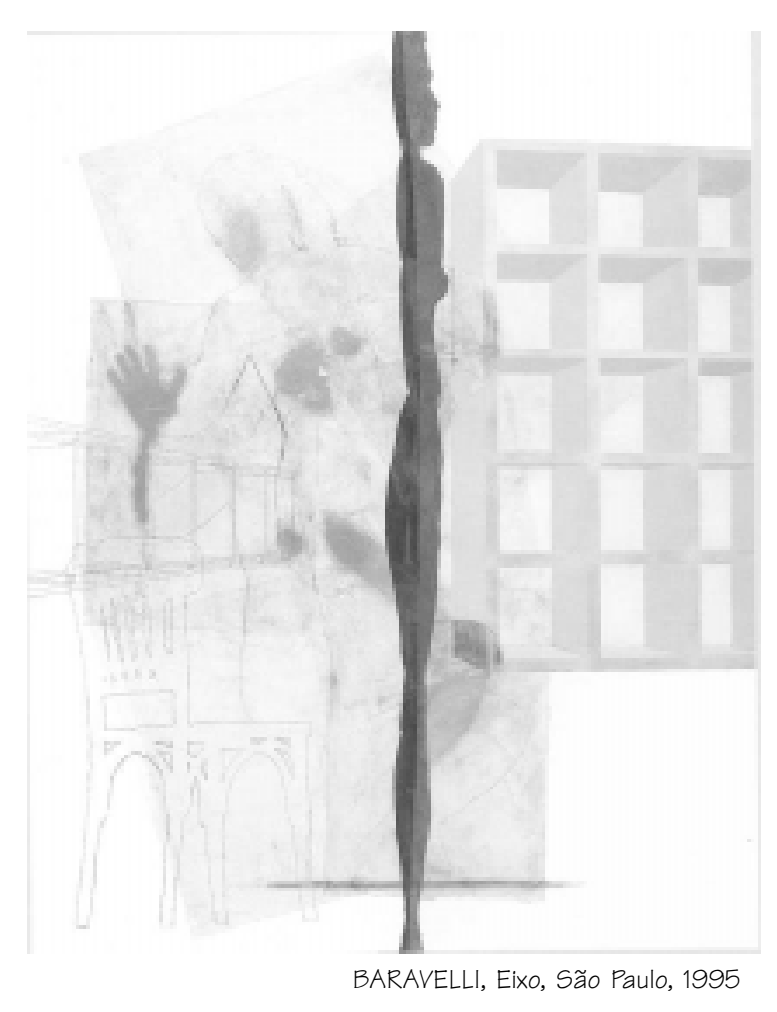

agosto, 2001 
homem-natureza, dizem respeito à idéia de que se eliminam, ou se secundarizam, os sujeitos históricos. Esses sujeitos são substituídos pela natureza vingativa e constróem uma visão apocalíptica da relação homemnatureza, cujo risco para o movimento ambientalista $e$ para a educação ambiental é a definição de estratégias de intervenção social autoritárias e descompromissadas com as possibilidades histórico-concretas de transformação social democrática.

Essa concepção de relação homem-natureza tem conseqüências para a formação dos educadores ambientais nos cursos de graduação. A educação, de prática social construída e construtora da humanidade e das relações homem-natureza e homem-homem, fica reduzida ao papel de adaptadora dos sujeitos ao mundo pré-determinado pelos processos naturais. A representação da educação como natural, indica a educação com função de reintegração do indivíduo à natureza (Russeau, 1995).

A formação dos educadores ambientais nos cursos de graduação das universidades fundamentada por essas concepções esvazia a função dos educadores como mediadores na interação dos indivíduos com o meio natural, social e cultural. Na concepção natural, a função dos educadores é de, supervalorizando as experiências sensíveis, sugerir a submissão do sujeito ao domínio natural da natureza. As mudanças pessoais internas - de caráter espiritualista - são metas educativas, e a adaptação do indivíduo ao ambiente natural e harmônico é princípio educativo. A idéia de relação homem-natureza natural aparece como reação dos professores/ pesquisadores - cientistas -, à lógica racionalista e antropocêntrica de domínio da natureza. Do ponto de vista lógico parece que essa reação, que se orienta pela negação da racionalidade ao articular uma proposta ahistórica de retorno dos indivíduos à condição pré-científica, implica a inversão da dominação antropocêntrica da natureza: para reprimir a dominação do homem sobre a natureza, sugere a dominação da natureza sobre o homem. A natureza, vingativa, submete o homem, arrogante, ao seu poder. Essa idéia está presente no discurso apocalíptico ambiental que acompanha e explicita essa concepção.

A crise ambiental e a profecia apocalíptica se relacionam, constituindo perigosos argumentos filosófico-políticos para atitudes autoritárias de controle social. Esse discurso, aparentemente ingênuo, tem conseqüências para a articulação entre os conhecimentos científicos e a organização da sociedade. Assim, a concepção de natureza natural, quando trazida como perspectiva de superação da lógica antropocêntrica da ciência moderna cristaliza, ao invés de superar, o projeto político-social autoritário e controlador da modernidade, construído sobre a lógica racionalista. Ao negar a lógica racional, a lógica natural, por seu caráter a-histórico, cristaliza os pressupostos sócio-culturais de uma organização social injusta e desigual, caracterizada pela exploração do homem pelo homem, tornando esses pressupostos imutáveis. O discurso ambiental aparece então carregado de ideologia, a ideologia da natureza natural como conteúdo educativo ideológico - da educação ambiental.

Por outro lado, a concepção racional é expressa pela idéia de que a relação homem-natureza é definida pela razão (Descartes, 1999) e a 
educação tem como função preparar o indivíduo para a vida em sociedade. Nesta concepção, predominante entre os professores dos cursos de Química mas presente, também, entre os professores dos outros grupos, implica, na área ambiental, o uso racional dos recursos naturais. Assim, se a razão - a objetividade -, faz-se presente para definir as relações dos seres humanos entre si e entre eles e o ambiente em que vivem, o ponto de partida da relação homem-natureza é determinado pelos conhecimentos - objetivos e inquestionáveis, porque científicos - produzidos por esses próprios homens, em cuja base social está a exploração. Aqui já não é mais a natureza natural que ocupa a centralidade da vida social, mas a ciência - empírica, mecânica, positiva, racional e cartesiana. Sob o argumento da neutralidade da ciência, ela, em sua dimensão social, contribui para a organização dos indivíduos numa sociedade racionalmente estruturada, cuja perspectiva estática da relação homem-natureza implica o domínio absoluto daquele que tem o poder sobre os conhecimentos: o ser humano.

Esta concepção de relação homem-natureza racional e dominadora tem conseqüências para a formação dos educadores ambientais. A educação, de prática social construída e construtora da humanidade, fica reduzida à função de, por um lado, transmitir os conhecimentos técnico-científicos que definem as relações homem-natureza e homem-homem e, por outro, de desenvolver formas eficientes de garantir essa transmissão (Comênio, 1957). A representação da educação como racional, indica a educação, em particular em sua dimensão ambiental, como a preparação - no sentido de adaptação - intelectual dos indivíduos para viverem em sociedade de forma a garantir que os recursos naturais não se esgotem. Constatada a crise da utilização dos recursos naturais pelo desenvolvimento dos conhecimentos ambientais, conquistado pelas ciências da natureza, a lógica que emerge do próprio desenvolvimento é a utilização racional desses recursos. Então, a Educação Ambiental tem como função adaptar os indivíduos à sociedade e esses às condições limitadas do ambiente natural. Essa adaptação se faz a partir da preparação intelectual: transmissão/aquisição de conhecimentos científicos acerca do ambiente.

Aos educadores ambientais cabe, segundo esta concepção, a função de transmissão, mecânica, desses conhecimentos. Os conteúdos de ensino são, principalmente, os conhecimentos acumulados pelas gerações $e$ transmitidos como verdades, mesmo que temporárias. Valores e atitudes, quando conteúdos de ensino, recebem o mesmo tratamento: transmissão/ aquisição de verdades. Esses conteúdos têm valor essencialmente intelectual, transformando o ato educativo, intrinsecamente dinâmico e construtivo, em propostas pedagógicas intelectualistas e academicistas de caráter mecânico e disciplinatório. Uma das conseqüências filosófico-políticas desta proposta educativa é a dominação. Parece que o saber confere e legitima ao educador ambiental - em todos os níveis e modalidades de educação e ensino - atitudes autoritárias de dominação. $O$ antropocentrismo da relação homem-natureza aparece, no processo educativo, sob a forma de autoritarismo. A assimilação, por imposição/adesão, é princípio educativo fundamental. 


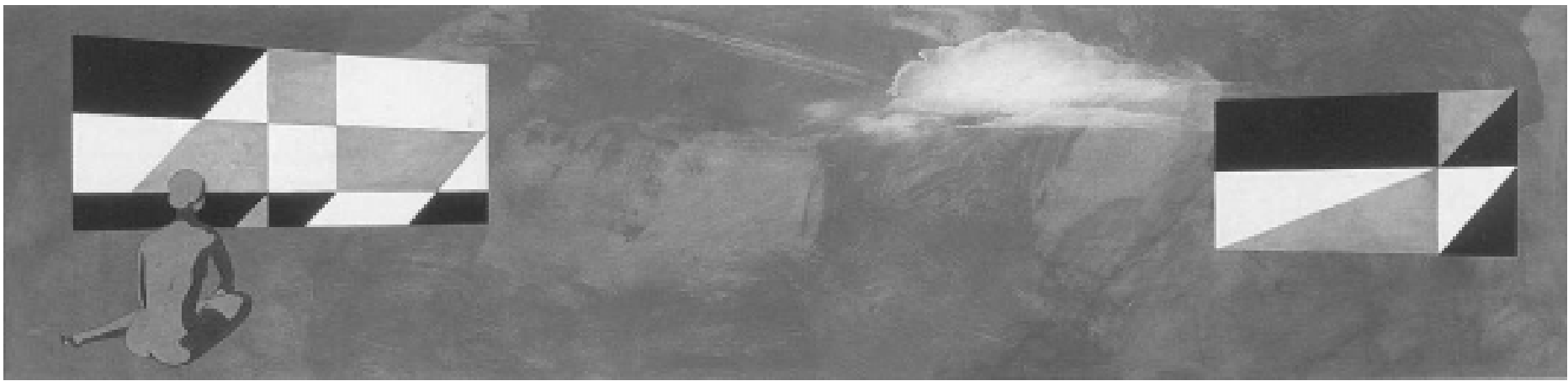

Se na relação homem-natureza e na educação, temos a razão e a imposição/adesão como princípios organizadores, no que diz respeito às relações sociais isso também se faz presente. A sociedade organizada segundo a lógica da razão instrumental é uma sociedade funcional. A funcionalidade legitima a imposição e, da mesma forma, produz a adesão.

A articulação entre a crise ambiental $e$ a profecia apocalíptica também está presente na concepção racional. Resultado do desenvolvimento dos conhecimentos técnico-científicos sobre os processos ecológicos do ambiente, também nesta concepção essa articulação aparece como argumento filosófico-político para atitudes autoritárias de controle social. A diferença aqui é que este discurso perde o caráter aparentemente ingênuo daquele que identificamos na concepção natural e ganha o argumento da autoridade científica. A ciência autoriza e legitima a submissão como necessidade vital, ameaçando a humanidade com o risco do descontrole social e ambiental total. Estamos sob a ideologia da razão; educação e sociedade têm de se submeter.

Muitas das atividades de Educação Ambiental nas universidades têm se caracterizado por transitar, do ponto de vista dos fundamentos teóricometodológicos, entre as concepções que aqui chamei de racionais e naturais. Essa prática educativa, em geral centrada na transmissão/aquisição dos conhecimentos sobre o ambiente, especialmente sobre os problemas de esgotamento de recursos (racional), aponta alternativas romantizadas (naturais) de forte apelo emocional para a organização da vida individual no que diz respeito à relação dos indivíduos com o ambiente em que vivem. Observa-se ainda que, nessas atividades, as abordagens natural e racional têm pontos em comum: ambas conferem à problemática ambiental uma abordagem catastrófica apocalíptica, como também desconsideram a influência concreta dos aspectos sócio-históricos desses problemas.

Uma das alternativas de pensar e agir a relação homem-natureza e a educação, para superação dos condicionantes históricos da modernidade nas ciências e na sociedade revelados por alguns professores entrevistados, principalmente os dos cursos de Geografia e os das disciplinas da área da Educação dos três cursos estudados, definiu a concepção histórica. Esta concepção implica, na área ambiental, considerar a perspectiva histórica para a compreensão tanto da crise ambiental atual quanto de sua superação. 
Assim, a história da organização das relações sociais define a relação homemnatureza $e$ as relações entre os homens; o ponto de partida dessas relações é a intencionalidade concreta (Marx, 1993). Quais as formas históricas de organização dos homens no ambiente em que vivem, e quais as formas de superação desse conjunto de relações em crise? Nesta concepção, a relação homem-natureza não é definida naturalmente pela natureza, nem é definida cientificamente pela razão, mas construída social e politicamente pelo conjunto dos homens, construção essa que também lança mão dos conhecimentos científicos sobre a natureza como elementos importantes, mas não exclusivos, do processo educativo. A idéia de neutralidade - da ciência e das formas científicas de organização social - é recusada. Totalidade $e$ intencionalidade são fundamentos da construção histórica da relação homem-natureza.

Esta concepção de relação homem-natureza, definida pela história das relações e práticas sociais, tem conseqüências para a formação dos educadores ambientais. A educação é construída no interior das relações sociais concretas de produção da vida social, assim como contribui para a construção dessas relações sociais. As implicações filosófico-políticas dessas afirmações dizem respeito à ampliação dos processos educativos na perspectiva da formação humana plena (Manacorda, 1991; entre outros), isto é, na perspectiva de superação radical da alienação, da exploração do homem pelo homem e da exploração da natureza pelos seres humanos. Nesse sentido, a educação instrumentaliza o sujeito para a prática social, inclusive em sua dimensão ambiental, instrumentalização que poderá ser tão democrática quanto for democrática a sociedade que a constrói e que é construída pelas relações sociais. O princípio educativo não é a ideologia da harmonia nem o fetiche do conhecimento científico, mas as efetivas necessidades histórico-concretas da sociedade, definidas por instrumentos democráticos de participação social.

No entanto, numa análise mais aprofundada, pode-se identificar neste quadro teórico, alguns sinais de crise de referenciais epistemológicos. A crise da modernidade, tanto no aspecto ambiental, quanto no sociocultural, vem colocando a necessidade de superação da lógica racional. Esta crise não é nova, apenas toma aparência de novidade quando se alastra por todos os setores da vida social, das ciências às práticas sociais, passando pela educação e pelo ensino. O processo de contradição aparece desvendado e a busca de alternativas está na ordem do dia.

A modernidade trouxe-nos a cientificidade e a organização social capitalista como cenário filosófico-político das relações dos homens na sociedade e na natureza. A degradação ambiental e o aprofundamento das desigualdades sociais engendram uma das maiores crises da modernidade, $e$, também, a urgente necessidade de sua superação. Ao contrário do que ideologicamente pretendem o conhecimento científico, pretensamente neutro, $e$ as teorias sociais conciliatórias, a ciência, a tecnologia e o capitalismo não são formas naturais - a-históricas - de desenvolvimento social, mas formas concretas, históricas, e por isso, com possibilidades de superação pelas ações humanas. 
Os educadores ambientais têm o papel de mediar a interação dos sujeitos com seu meio natural e social; para exercer esse papel, conhecimentos vivos e concretos tornam-se instrumentos educativos. A educação sistematizada tem papel sócio-cultural relevante e indissociável às práticas sociais. Esta sistematização, porém, não obedece à lógica formal - racional - mas à sistematização de conhecimentos, valores e atitudes de conteúdos culturais ambientais, sociais e políticos que contribuam para a construção não só de uma relação mais equilibrada entre o homem e a natureza, mas também de uma relação equilibrada entre os homens. Assim, os conhecimentos técnicocientíficos sobre os processos ambientais só têm sentido como conteúdos educativos da Educação Ambiental se ligados de forma indissociável aos significados humanos e sociais desses processos. Os valores e atitudes só têm sentido se a essência do bom tiver dimensão histórica, isto é, se for pensada no movimento histórico intencional do permanente vir a ser dos sujeitos articulando os interesses coletivos e individuais. Nesse sentido, o processo de humanização do indivíduo, preocupação central da educação, é um processo de apropriação da própria humanidade, produzida pelos homens através da história (Saviani, 1994). Isto quer dizer que a dimensão histórica do processo educativo diz respeito à transmissão (no sentido de apropriação) das experiências sócio-culturais da humanidade, ou seja, à valorização da transmissão/apropriação dos conhecimentos, valores $e$ atitudes produzidos pelo conjunto dos indivíduos. Os conhecimentos e a moral perdem o caráter de exterioridade social conferido pela pretensa objetividade da concepção racionalista de ciência e de sociedade - por conseqüência, da educação e do ensino - para constituir a ética e o conjunto de conhecimentos sóciohistóricos, instrumentos de humanização e de socialização, instrumentos vivos de fazer a vida. Conhecimentos, no que diz respeito à dimensão ambiental da educação, são os conhecimentos dos processos sócio-culturais da humanidade, conhecimentos das escolhas sociais, assim como os valores $e$ atitudes dizem respeito à ética das relações homem-natureza e das relações entre os sujeitos. Assim, numa perspectiva histórica de Educação Ambiental, os conteúdos educativos articulam natureza, história e conhecimento, além de valores $e$ atitudes como respeito, responsabilidade, compromisso $e$ solidariedade.

Desta forma, Educação Ambiental é uma dimensão da educação, é atividade intencional da prática social, que imprime ao desenvolvimento individual um caráter social em sua relação com a natureza e com os outros seres humanos, com o objetivo de potencializar essa atividade humana, tornando-a mais plena de prática social e de ética ambiental. Essa atividade exige sistematização por meio de metodologia que organize os processos de transmissão/apropriação crítica de conhecimentos, atitudes e valores políticos, sociais e históricos. Assim, se a educação é mediadora na atividade humana, articulando teoria e prática, a Educação Ambiental é mediadora da apropriação, pelos sujeitos, das qualidades e capacidades necessárias à ação transformadora responsável diante do ambiente em que vivem. Pode-se dizer que a gênese do processo educativo ambiental é o movimento de fazerse plenamente humano pela apropriação/transmissão crítica $e$ transformadora da totalidade histórica e concreta da vida dos homens no 
ambiente.

À aparente ingenuidade da concepção natural de ciência $e$ de sociedade, $e$ à lógica formal da concepção racional, contrapõem-se a crítica e a lógica dialéticas. Aos pressupostos de organização do mundo natural e social préestabelecidos (pela natureza e pela razão), a dialética oferece o movimento histórico das partes do todo, construído pelos sujeitos históricos. Nesse sentido, a totalidade colocada pela lógica dialética não é a totalidade reducionista das concepções que naturalizam a relação homem-natureza $e$ a educação, a redução das partes ao todo, mas uma totalidade dialética porque contraditória - $e$ histórica - em que a ideologia $e$ a alienação se apresentam à superação -, uma totalidade na qual a igualdade e a diversidade não se contrapõem, mas coexistem, constituindo formas sociais democratizadoras. A utopia da totalidade, tão valorizada na área ambiental $e$ na Educação Ambiental, na perspectiva histórica, transforma-se, não só na utopia ambiental, mas na utopia ambiental e democrática (Santos, 1997). Educação Ambiental construída na relação entre os conhecimentos e as relações sociais constrói e é construída no e pelo novo paradigma da responsabilidade da ação humana na natureza e na sociedade.

Pelo que foi apresentado até aqui, e com relação aos referenciais filosófico-políticos analisados, percebe-se a presença marcante de uma tendência: a necessidade de superar o paradigma racionalista da ciência moderna. Pensando sobre os referenciais teóricos presentes nas atividades de formação dos educadores ambientais, identificam-se sinais de transição de paradigmas (Kuhn, 1987; Santos, 1995). Assim, há possibilidades concretas de que a formação dos educadores ambientais nas universidades possa ser construída a partir de práticas educativas que ajudem na superação das formas fragmentadas do pensar e agir. Para isso, essas práticas educativas podem ser organizadas sob o paradigma da interdisciplinaridade, radical $e$ intencionalmente construídas nos cursos de graduação, mesmo que para isso seja preciso superar as formas acadêmicas atuais de organização do ensino, da pesquisa e da extensão.

Esta tendência sinaliza o movimento de procura e transição de paradigmas científicos e, de certa forma, sócio-culturais. Este movimento diz respeito à superação do paradigma dominante principalmente nas ciências naturais. No entanto, as análises das falas dos professores revelaram uma idéia de superação que se aproxima da idéia de negação. Superação, numa perspectiva dialética, não é negar, mas avançar, ou seja, incorporar criticamente o paradigma dominante construído pela história do desenvolvimento das ciências e da organização social, $e$ ir além, construir, sobre a base histórica do pensamento científico e sobre as formas de organização sociais reais, novas formas, alternativas, de ação humana na natureza e na sociedade. Desta forma, a utopia perde a abordagem ingênua que caracteriza o movimento de superação/negação, de volta às condições pré-científicas da relação homem-natureza, nas quais a história real, concreta e material é desconsiderada, e ganha a abordagem histórica, a possibilidade de construção de alternativas civilizatórias para as relações homem-natureza e homem-homem. Na construção de novos paradigmas para as relações sociais trata-se de criar novas ciências e tecnologias que 
resultem de e em um novo modelo de sociedade, ecológica e democrática, um novo modelo civilizatório igualitário que pode encontrar no pensamento socialista, inspiração revolucionária.

A crise dos paradigmas e os novos princípios metodológicos para a organização da formação de educadores ambientais no ensino superior

A temática ambiental pode ser uma das sínteses possíveis da crise dos paradigmas da ciência e da organização social, pois os novos e profundos problemas colocados por ela não obtiveram resposta da ciência e não podem ser pensados - no sentido de sua superação - no modelo social, político e econômico de exploração da natureza e dos homens.

Assim, a prática educativa ambiental, desenvolvida pelos educadores formados nos cursos de graduação, traz, em sua formação, condicionantes sócio-históricos. A complexa relação entre sociedade e educação define o cenário da formação dos educadores. Desta forma, não se pode pensar a formação dos educadores - $e$ a formação dos educadores dos educadores ambientais - como solução definitiva para os problemas socio-ambientais. Considerando a amplitude e a complexidade do campo de atuação profissional dos educadores ambientais, a universidade tem reduzido a função desses profissionais - todos aqueles que vão trabalhar com a temática ambiental - à dimensão técnica da atuação profissional no mundo do trabalho, mundo esse complexo e contraditório, mas concreto e histórico. Aqui se coloca a escolha entre a concepção ampliada e a concepção restrita de formação profissional dos nossos alunos. A ideologia da eficiência tem sido um forte obstáculo à formação crítica dos profissionais no ensino superior, alojada na organização fragmentada dos recortes disciplinares do conhecimento. Esta visão utilitária e mercantil de eficiência evita deliberadamente o pensar, na formação profissional, da prática social que a define e que é por ela definida.

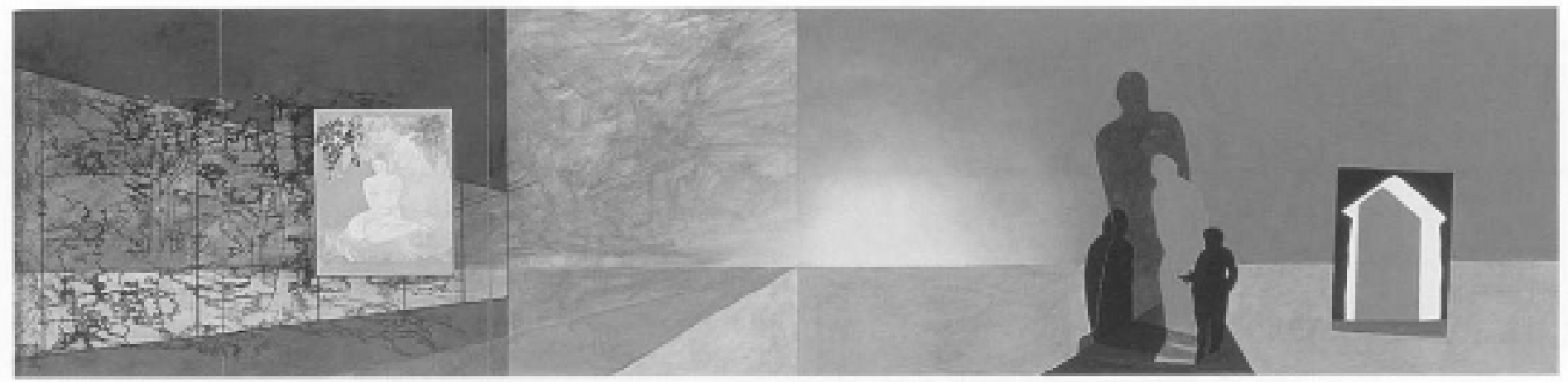


A dimensão ambiental das relações sociais exige dos profissionais dessa área, e particularmente do educador ambiental, o exercício de uma função social de síntese, isto é, que seja formado na perspectiva de integrar os conhecimentos e a cultura com a formação sócio-ambiental dos sujeitos ecológicos. Trata-se então de colocar, como eixo do processo de formação dos educadores ambientais nos cursos de graduação, a formação de um profissional de sínteses. A idéia de totalidade, que daqui emerge, responde à idéia de totalidade presente no conceito de Ecologia, muitas vezes esquecido. Formar profissionais de Educação Ambiental, com competência para formular sínteses sócio-ambientais, exige um esforço criativo nos cursos de graduação, inclusive de reformulação formal dos currículos. Reformulação radical que, as universidades, pelo menos no que diz respeito à circulação de idéias sobre novos paradigmas, estão a solicitar, embora suas estruturas institucionais sejam grande obstáculo.

A formação dos educadores ambientais no ensino superior se dá de forma assistemática, resumindo-se praticamente a três tipos de ação desconectadas: tratamento de temas ambientais nas disciplinas afins, disciplinas optativas de Educação Ambiental e formação educativopedagógica - nas diferentes especialidades - oferecida pelas disciplinas da área de Educação nas licenciaturas. Embora considere a presença significativa de atividades com a temática ambiental, as oportunidades de reflexão oferecidas, sobre as diferentes concepções de relação homem-natureza e de educação, que são, nas situações de ensino, categorias importantes para integrar os conteúdos da formação dos educadores ambientais, são poucas $e$ superficiais. Sequer os fundamentos da prática docente são postos em discussão, mas incorporados e praticados, mesmo que de forma invisível pelos próprios professores formadores de educadores ambientais.

Estamos vivendo, na ciência e na sociedade, um momento de transição de paradigmas e, justamente no ensino superior, espaço social privilegiado de discussão científica, essa transição é sentida, mas não é problematizada nas atividades de formação humana e profissional. O tom racional da crítica ao antropocentrismo, presente na fala dos professores investigados, revela que o paradigma racional, no ensino sobre o ambiente, não foi superado por aqueles que conferem à temática ambiental uma abordagem natural, nos quais identifico os mais fortes sinais do movimento de transição de paradigmas. Os conhecimentos científicos sobre os processos ecológicos aparecem como argumento racional, e até certo ponto dominador, de recolocar o ser humano em seu lugar, definido naturalmente. Essa atitude educativa, essencialmente disciplinadora, não traz em seu interior sinais de transformações paradigmáticas nas atividades de ensino.

Essa ênfase nos conhecimentos científicos como legitimadores de práticas educativas ambientais disciplinadoras, combina com a tendência dominante da organização da pesquisa, do ensino e da extensão na universidade. Sabese que as atividades de ensino e de extensão não são tão valorizadas quanto as atividades de pesquisa. Por outro lado, as idéias de integração, presentes nas falas da grande maioria dos professores entrevistados, refere-se à integração de atividades de ensino. Esta contradição, no entanto, pode ser um importante sinal de transição paradigmática no ensino. Percebo que, se 
na dimensão epistemológica da Educação Ambiental há sinais evidentes de transição de paradigmas, na dimensão pedagógica a situação parece um pouco mais complicada. De um lado, aparece nas falas dos professores o conservadorismo educativo, revelando concepções educacionais muito arraigadas no paradigma dominante racionalista das relações indivíduo sociedade - educação. De outro lado, a idéia de interdisciplinaridade se faz presente de forma tão intensa nessas falas, que tem que ser considerada como um forte indicativo de transformação paradigmática em busca da totalidade, como síntese teórico-prática das atividades de ensino. Estamos vivendo então, nas universidades, uma turbulência de referenciais que as capacita para transformações profundas, se enfrentados os aspectos estruturais que despotencializam esse movimento.

Por outro lado, sabe-se que na formação dos docentes do ensino superior nos cursos de pós-graduação nos quais, geralmente, se completa a formação dos professores pesquisadores, a universidade privilegia a pesquisa $e$ desvaloriza as atividades de ensino. Essa situação pode ser percebida não só pela análise das propostas curriculares dos cursos de pós-graduação e pelas críticas referentes à competência didático-pedagógica dos professores pelos seus alunos, mas, principalmente, pela análise do discurso oficial e cotidiano dos coordenadores e professores dos cursos de mestrado e doutorado, nos quais, pelo menos do ponto de vista formal, formam-se os professores das universidades públicas. Centrada na pesquisa, essa formação, no que diz respeito à formação pedagógica dos pesquisadores/professores, traz expectativas que se relacionam quase que tão somente às competências didático-metodológicas da prática educativa em sua dimensão técnica. Nos cursos de graduação essa problemática se faz ainda mais presente. Além do descaso com a formação pedagógica a que são submetidos esses professores, o distanciamento, físico e intelectual, entre as chamadas disciplinas de conteúdo específico e as disciplinas pedagógicas só faz agravar o problema de formação dos professores. Estabelecer parcerias sistematizadas entre as unidades acadêmicas da área de educação $e$ as unidades acadêmicas das áreas específicas é uma necessidade no ensino superior, até mesmo como forma de criar condições objetivas para o desenvolvimento de trabalhos interdisciplinares.

Isso remete à discussão sobre a estrutura e o funcionamento das instâncias universitárias. A organização interdisciplinar das atividades de ensino nas universidades, de certa forma, exige a superação da estrutura departamental obsoleta, estabelecida por políticas educacionais autoritárias já historicamente superadas. Os departamentos tornaram-se hoje instâncias essencialmente burocráticas, onde as discussões políticas e acadêmicas são reprimidas em nome de uma praticidade racional ou em nome da ideologia da harmonia. Os conflitos são estrategicamente esvaziados de seus conteúdos políticos e acadêmicos, dos quais emergem conflitos paradigmáticos potencialmente enriquecedores da prática pedagógica.

Não se pode negar que, nos últimos anos, a universidade conseguiu avançar no processo de democratização, quebrando, na prática, a estrutura de seu funcionamento imposta por políticas e legislação autoritárias. No entanto, esse processo de democratização contém todas as contradições 
resultantes do momento histórico-social que estamos vivendo. Alguns problemas precisam ser urgentemente enfrentados sob o risco de cristalizar essas conquistas históricas, transformando-as em obstáculos à reestruturação das atividades acadêmicas. Entre esses problemas, destaca-se o excesso de controle burocrático, que impede o funcionamento das universidades públicas e a necessidade de autonomia, em especial da autonomia interna, da autonomia de suas instâncias de decisão, para a melhoria da qualidade do ensino e da produção dos conhecimentos. Em quase todas as universidades públicas vêm acontecendo discussões de propostas de reestruturação interna que procuram resgatar a função social dessa instituição no contexto sócio-histórico. A tendência é a integração de atividades que consigam atender à crescente demanda social com um ensino de qualidade e uma produção científica que responda ao desenvolvimento do País. A racionalização e aplicação dos recursos e a busca de formas mais ágeis, modernas e eficientes, são diretrizes presentes nas propostas de administração.

No entanto, uma questão básica se coloca nesse processo de reestruturação. Para onde queremos ir? A operacionalização das idéias neoliberais, pressionada pela globalização - leia-se dependência - da economia mundial, leva à necessidade, segundo seus defensores, de reestruturação do Estado. A desregulamentação pressupõe a saída do Estado não só do setor de produção mas também dos serviços públicos. Os direitos sociais, tratados como mercadorias, são colocados no setor de serviços, serviços dos quais o Estado vai se desobrigando. Dentre esses direitos sociais encontram-se a educação e, conseqüentemente, o ensino superior.

A educação ocupa um papel estratégico no projeto neoliberal. De um lado, de preparação para o trabalho, garantia de formação do trabalhador sob nova base técnica. De outro, a consolidação da educação, inclusive a escolar, com função ideológica, de transmitir as idéias neoliberais. $\mathrm{O}$ processo educativo pretendido incorpora as idéias de organização social oriundas desse projeto político: competição, individualismo, busca da qualidade etc.

$\mathrm{Na}$ educação escolar, as instituições de ensino e, entre elas, as instituições de ensino superior, têm sido alvo das reformas políticas e sociais do projeto neoliberal. O Banco Mundial, organismo internacional que, junto com o FMI, vem impondo programas de estabilização e ajuste da economia brasileira, tem traçado também diretrizes para as políticas de ensino superior no Brasil. A meta, dentro do ideário neoliberal, é a transformação, autorizada, das universidades em empresas econômicas. Autorizada porque a política para o ensino superior pressupõe que as Universidades aceitem se reorganizar em busca da qualidade e da eficiência. A estratégia dos governos tem sido o abandono das Instituições de Ensino Superior à sua própria sorte, até que, no esgotamento, elas procurem - ou seja, aceitem soluções que, a rigor, descaracterizam sua função de produção autônoma $e$ distribuição democrática do conhecimento e, principalmente, da cultura (Pires \& Tozoni-Reis, 1999).

As reformas para a educação superior, pelo menos até agora, não pretendem a privatização explícita das instituições de ensino superior, mas 
caracterizam uma política privatista dissimulada. Esta estratégia significa criar instituições diferenciadas de ensino superior, com tarefas diferenciadas no que diz respeito à produção $e$ à transmissão dos conhecimentos, instituições em que a produção e distribuição da cultura - e não só dos conhecimentos - vai perdendo espaço. As universidades públicas perdem assim o princípio da articulação - a indissociabilidade - entre ensino, pesquisa e extensão. $O$ que isto pode significar para a pesquisa e para a formação dos nossos alunos?

Dentro do ideário neoliberal, a desobrigação do Estado quanto ao financiamento das atividades das universidades públicas é visível. A busca de fontes alternativas de financiamento põe em risco um dos princípios básicos da universidade: a autonomia. A dependência das universidades de setores diretamente inseridos no mercado numa sociedade capitalista como a nossa, pode significar alto risco para a produção, independente, de conhecimentos e elaboração da cultura. As decisões sobre a pesquisa, por exemplo, passam agora a ser dirigidas segundo as necessidades do mercado. A desvalorização dos educadores/pesquisadores viabilizada pela deterioração de seus salários nas universidades públicas é mais uma estratégia para seu desmantelamento.

Assim, os serviços públicos de educação estariam totalmente inseridos nas exigências do mercado globalizado, sob a hegemonia das idéias neoliberais. $\mathrm{O}$ tom das reformas pretendidas para a educação superior é o da eficiência e racionalidade. As estratégias de caráter administrativo racionalizador escondem a intenção de descaracterização das instituições de ensino superior como instituições sociais de produção autônoma e desinteressada de conhecimento e de cultura, submetendo-as às novas formas de organização do capitalismo, usando-as como mais um instrumento de controle a seu favor. Caminhamos para a transformação dessas instituições em espaços políticos sem autonomia, sem efetiva participação social e sem a possibilidade de colaborar para a construção histórica e social do futuro.

Neste cenário acontece, ainda que de forma assistemática, a formação dos educadores ambientais nos cursos de graduação. Para pensar na organização da Educação Ambiental nas universidades, é preciso pensar também na formação dos professores formadores dos educadores ambientais. Convivemos hoje nas universidades não só com uma organização curricular fragmentada do ponto de vista do ensino, mas com uma organização também fragmentada da pesquisa. Assim, vejo que, para pensarmos um projeto competente para a universidade numa perspectiva de transformação paradigmática, é preciso superar as formas de organizar o ensino, a pesquisa $e$ a extensão. Penso que só formas acadêmicas autônomas, que substituam radicalmente as formas burocráticas de convivência entre diferentes professores e diferentes áreas do conhecimento, podem garantir as trocas necessárias à construção deste objetivo. Projetos interdisciplinares, em substituição à organização departamental, podem garantir a articulação entre as áreas do conhecimento e se construir sobre a indissociabilidade real e concreta do ensino, da pesquisa e da extensão como alternativa para garantir a formação dos professores formadores dos educadores ambientais. 
Pensar a formação dos educadores ambientais nos cursos de graduação das universidades, hoje, significa ter como referência a idéia de totalidade, totalidade dos campos pedagógico, político, social e científico. A

interdisciplinaridade, assim como a articulação entre as atividades de ensino, pesquisa e extensão, é princípio metodológico para estruturar e sistematizar essa formação.

No entanto, interdisciplinaridade não significa apenas a articulação formal entre as disciplinas hoje existentes, mas exige uma definição paradigmática. A universidade, para o enfrentamento dos desafios sociais $e$ políticos que hoje estão a ela colocados, precisa enfrentar desafios paradigmáticos de transformação estrutural profunda, terá que transformar o ensino, a pesquisa $e$ a extensão pela construção radical da totalidade. Nesse sentido, a formação dos educadores ambientais será pontuada pela idéia de que o ambiente é cada vez mais, se considerarmos todo movimento de arranjos no capitalismo internacional, um fenômeno social. Estudar a natureza é, cada vez mais, tomar decisões histórico-científicas sobre a relação homem-natureza.

$\mathrm{O}$ paradigma da totalidade histórica possibilita a interdisciplinaridade $e$, nesse sentido, as ciências ambientais apresentam-se como espaço acadêmico e científico privilegiado das transformações, porque são paradigmáticos quando pensamos em transformações das formas de conceber e fazer a ciência $e$ a sociedade.

Assim, penso que a formação dos educadores ambientais nos cursos de graduação pode ser sistematizada, numa perspectiva de inovação paradigmática, no interior de um projeto de reestruturação radical do ensino, da pesquisa e da extensão. A interdisciplinaridade passa a ser o princípio metodológico básico nessa reestruturação. Nos cursos de graduação, essa reestruturação pode organizar a integração de disciplinas das diferentes áreas do conhecimento, a integração teoria e prática, a integração ensino, pesquisa e extensão. Qualquer modelo de reestruturação que partir - no sentido de superar -, de formas históricas da organização das atividades, tem maiores possibilidades de responder às expectativas $e$ necessidades da realidade concreta e dos caminhos possíveis, abertos por essa realidade turbulenta que caracteriza a transição de paradigmas.

\section{Referências bibliográficas:}

CAMPOS, M. M. F. Educação Ambiental e paradigmas de interpretação da realidade: tendências reveladas. Campinas, 2000. Tese (Doutorado). Faculdade de Educação,

Universidade Estadual de Campinas.

CAPRA, F. O ponto de mutação: a ciência, a sociedade e a cultura emergente. 9.ed. São Paulo: Cultrix, 1993.

COMENIO, J. A. Didáctica Magna. 3.ed. Lisboa: Calouste Gulbenkian, 1957.

DESCARTES, R. Discurso do método. São Paulo: Nova Cultural, 1999. (Os Pensadores)

KUHN, T.S. A estrutura das revoluções científicas. São Paulo: Perspectiva, 1987.

MANACORDA, M. A. Marx e a pedagogia moderna. São Paulo: Cortez, 1991.

MARX, K. Contribuição à crítica da economia política. São Paulo: Martins Fontes, 1983. 
MARX, K. Manuscritos económicos-filosóficos. Lisboa: Edições 70, 1993.

MARX, K. O Capital: crítica da economia política. Rio: Civilização Brasileira, 1968.

MARX, K., ENGELS, F. A ideologia alemã. São Paulo: Hucitec, 1979.

MORIN, E., MARQUES, A. O problema epistemológico da complexidade. Lisboa: Publicações

Europa América, s.d.

PIRES, M.F.C. O materialismo histórico-dialético e a educação. Interface - Comunic., Saúde,

Educ., n.1, p.83-94, 1997.

PIRES, M. F. C., TOZONI-REIS, J. R. Globalização, Neoliberalismo e Universidade: algumas

considerações. Interface - Comunic., Saúde, Educ., n.4, p.29-39, 1999.

PRIGOGINE, I., STENGERS, I. A nova aliança. 3.ed. Brasília: Editora da UnB, 1997.

ROUSSEAU, J. J. Emílio: ou da educação. São Paulo: Martins Fontes, 1995.

SANTOS, B.S. Um discurso sobre as ciências. Lisboa: Afrontamento, 1995.

SANTOS, B.S. Pela mão de Alice: o social e o político na pós-modernidade. 4.ed. São Paulo:

Cortez, 1997.

SAVIANI, D. Educação: do senso comum à consciência filosófica. 10.ed. São Paulo: Cortez, 1991.

SAVIANI, D. Pedagogia histórico crítica: primeiras aproximações. 4.ed. São Paulo: Autores

Associados, 1994.

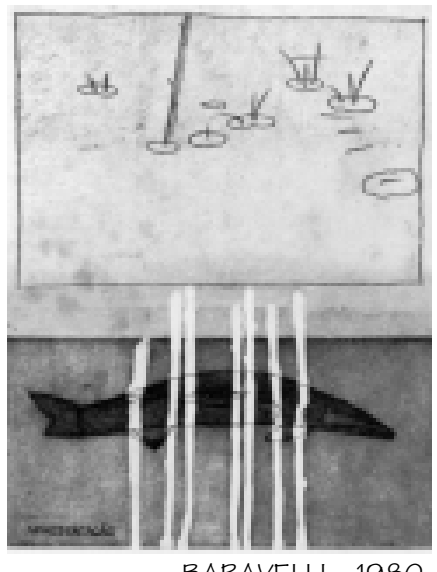

BARAVELLI, 1980

TOZZONI-REIS, M. F. C. Educación ambiental: referencias teóricas en la enseñanza superior, Interface - Comunic, Saúde, Educ, v.5, n.9, p.33-50, 2001.

Este artículo trata de los presupuestos teóricos presentes en la formación de los educadores ambientales en los cursos de graduación. Esos presupuestos definen un cuadro teórico analizado a partir del referencial metodológico del materialismo históricodialéctico. Ese cuadro teórico puede ser organizado en concepciones naturales, racionales $e$ históricas de la relación hombre-naturaleza y de la educación y sus análisis sugieren principios metodológicos de organización curricular en esos cursos.

PALABRAS CLAVE: Educación; educación ambiental; naturaleza; modelos teóricos.

Recebido para publicação em: 26/04/01. Aprovado para publicação em: 08/06/01. 